\title{
C5 Deficiency
}

National Cancer Institute

\section{Source}

National Cancer Institute. C5 Deficiency. NCI Thesaurus. Code C9469.

A rare genetic disorder with an autosomal recessive pattern of inheritance. It is caused by the ineffective or decreased biosynthesis of the fifth complement component, C5. C5 deficiency may also be acquired acutely post-infection. If C5 is adequately synthesized, its rapid depletion may result in a functional deficiency. Clinical signs of the inherited deficiency present within the second decade of life and are consistent with the signs of recurrent systemic infection. Deficiency of serum C5 and its major cleavage product, C5b, a component of the membrane attack complex, increases susceptibility to Neisserial infections. 